\title{
Percepção do Adolescente frente à sua Condição de Adoecimento Oncológico
}

doi: https://doi.org/10.32635/2176-9745.RBC.2021v67n4.1672

\author{
Perception of the Adolescent in face of its Condition of Oncological Sickening \\ Percepción de los Adolescentes ante su Condición de Enfermedad Oncológica
}

Vânia Chagas da Costa'; Nathália Rodrigues Martins de Melo²; Monique Maria de Lima Nascimento ${ }^{3}$; Deuzany Bezerra de Melo Leão ; Carlos Alberto Domingues do Nascimento5; Magaly Bushatsky ${ }^{6}$

\section{RESUMO}

Introduçáo: $\mathrm{O}$ adoecimento por câncer traz uma rotina cansativa por conta das terapêuticas agressivas, e ocorrem mudanças na vida do adolescente. Objetivo: Compreender a percepção do adolescente frente à sua condição de adoecimento oncológico. Método: Pesquisa exploratória, descritiva, qualitativa, por meio da técnica do discurso do sujeito coletivo, realizada com 13 adolescentes, no período de junho a agosto de 2019, no Centro Especializado em Oncologia Pediátrica de um hospital universitário. As entrevistas individuais foram gravadas baseadas nos seguintes questionamentos: Para você, como é estar doente? O que você pensa sobre seu futuro? Como você se relaciona com seus familiares e com a equipe de saúde? Resultados: Foram identificadas oito ideias centrais, entre elas: estar doente é ruim porque limita rotinas da vida normal; o tratamento é doloroso e altera minha imagem corporal; estar doente tem um lado bom; ficar curado e retomar planos para minha vida; o hospital e a equipe de saúde são acolhedores; falta empatia e acolhimento adequado; humanização na assistência; e apoio familiar. Conclusáo: Na percepção do adolescente, o adoecimento vai além da condição de saúde física, interfere e limita sua qualidade de vida e dos familiares, e a escuta terapêutica é essencial para uma assistência humanizada.

Palavras-chave: Adolescente; Neoplasias; Enfermagem Oncológica; Pesquisa Qualitativa; Saúde do Adolescente Institucionalizado.

\section{ABSTRACT}

Introduction: Cancer illness brings a tiresome routine due to aggressive therapies, and changes occur in the adolescent's life. Objective: Understand the perception of the adolescent in face of its condition of oncological sickening. Method: Exploratory, descriptive, and qualitative research, through the Collective Subject Discourse technique, conducted with 13 adolescents, from June to August 2019, at the Specialized Center for Pediatric Oncology of a university hospital. The individual interviews were recorded based on the following questions: What is it like to be sick to you? What do you think about your future? How do you relate to your family members and the health team? Results: Eight central ideas were identified, among them: being sick is bad because it limits normal life routines; the treatment is painful and changes my body image; being sick has a good side; be healed and resume plans for my life; the hospital and the team are welcoming; proper welcome and empathy are lacking; humanized care; family support. Conclusion: In the adolescent's perception, illness goes beyond the physical health condition, interferes, and limits theirs and their family quality of life, and therapeutic listening is essential for humanized care.

Key words: Adolescent; Neoplasms; Oncology Nursing; Qualitative Research; Health of Institutionalized Adolescents.

\section{RESUMEN}

Introducción: La enfermedad del cáncer trae una rutina agotadora debido a terapias agresivas, y se producen cambios en la vida del adolescente. Objetivo: Entender la percepción de lo adolescente ante su condición de enfermedad oncológica. Método: Investigación exploratoria, descriptiva y cualitativa, a través de la técnica de Discurso de Sujeto Colectivo, realizada con 13 adolescentes, de junio a agosto de 2019, en el Centro Especializado de Oncología Pediátrica de un hospital universitario. Las entrevistas individuales fueron grabadas basándose en las siguientes preguntas: ¿Cómo es estar enfermo para usted? ¿Qué opinas de tu futuro? ¿Cómo se relaciona con los miembros de su familia y el equipo de salud? Resultados: Se identificaron ocho ideas centrales, entre ellas: estar enfermo es malo porque limita las rutinas normales de vida; el tratamiento es doloroso y cambia mi imagen corporal; estar enfermo tiene un lado bueno; ser sanado y reanudar los planes para mi vida; el hospital y el equipo de salud son acogedores; carecer de empatía y bienvenida adecuada; humanización en el cuidado; y apoyo familiar. Conclusión: En la percepción del adolescente, la enfermedad va más allá de la condición de salud física, interfiere y limita su calidad de vida y familiares, y la escucha terapéutica es esencial para la atención humanizada. Palabras clave: Adolescente; Neoplasias; Enfermería Oncológica; Investigación Cualitativa; Salud del Adolescente Institucionalizado.

\footnotetext{
1-6Universidade de Pernambuco. Faculdade de Enfermagem Nossa Senhora das Graças. Recife (PE), Brasil.

'E-mail: vania.costa@upe.br. Orcid iD: https://orcid.org/0000-0002-1992-2879

2E-mail: nathaliarodriguesmelo@hotmail.com. Orcid iD: https://orcid.org/0000-0003-0307-4091

3E-mail: moniquemariadelima7@gmail.com. Orcid iD: https://orcid.org/0000-0002-5236-2834

${ }^{4}$ E-mail: deuzany.leao@upe.br. Orcid iD: https://orcid.org/0000-0002-5510-0733

${ }^{5}$ E-mail: carlos.alberto@upe.br. Orcid iD: https://orcid.org/0000-0002-0097-8303

${ }^{6} \mathrm{E}-\mathrm{mail}$ : magaly.bushatsky@upe.br. Orcid iD: https://orcid.org/0000-0002-0792-6469
}

Endereço para correspondência: Vânia Chagas da Costa. Rua Arnóbio Marques, 310 - Santo Amaro. Recife (PE), Brasil. CEP 50100-130. E-mail: vania.costa@upe.br 


\section{INTRODUÇÃO}

O câncer tornou-se um problema de saúde pública universal, e está entre as principais causas de mortalidade, sobretudo em crianças e adolescentes ${ }^{1}$. Em 2017, representou a sexta causa de mortalidade e a nona de morbidade, em todo o mundo, na faixa etária de 0 a 19 anos $^{2}$. No Brasil, nesse mesmo ano, ocorreram 2.553 óbitos na mesma faixa etária ${ }^{3}$.

De acordo com o Instituto Nacional de Câncer José Alencar Gomes da Silva (INCA) ${ }^{3}$, para cada ano do triênio 2020-2022, a projeção é de 8.460 novos casos de câncer na faixa etária de 0 a 19 anos, o que corresponde a um risco estimado de 137,87 casos novos por milhão/ano em meninos e de 139,04 por milhão/ano em meninas.

$\mathrm{O}$ acometimento em crianças e adolescentes está relacionado a fatores genéticos, de caráter idiopático, afetando normalmente as células do sistema sanguíneo, o sistema nervoso central e tecidos de sustentação. Com período de latência curto, crescimento acelerado e mais invasivo, entretanto, com melhor reação ao tratamento e um bom prognóstico, dependendo do tipo e do estágio a partir do diagnóstico ${ }^{4}$. Aproximadamente $80 \%$ dos cânceres em crianças e adolescentes são curáveis, se diagnosticados precocemente e tratados em centros especializados ${ }^{3}$.

Considerando a condição de adoecimento por câncer e diante de uma rotina cansativa por conta das terapêuticas agressivas, ocorrem mudanças na vida do adolescente e família, que estão relacionadas a várias internaçôes, níveis de estresse elevados, raiva, ruptura de laços familiares, quebra da rotina, desgaste mental, dor, angústia e medo da morte ${ }^{5}$.

Neste contexto, o enfermeiro, por ser um dos profissionais mais próximos aos pacientes, assume um papel fundamental no tripé: paciente oncológico, família e equipe de enfermagem, oferecendo o suporte não só na parte clínica, terapêutica e técnica, mas também focando em humanização, conforto, alívio dos sintomas e equilíbrio com intuito de alcançar a escuta terapêutica aberta e acolhedora ${ }^{6}$, o que possibilita a compreensão de angústias, medos, oferta suporte emocional imediato, e faz com que o cuidado seja mais efetivo ${ }^{7}$.

Durante o processo terapêutico, a relação profissional-paciente se faz importante no sentido de se colocar no lugar do outro e exercer a empatia, para poder entender as necessidades de quem é cuidado. A ferramenta da escuta terapêutica é essencial e deve ser aplicada por profissional qualificado, pois corre o risco de trazer consequências negativas, quando mal utilizada ${ }^{8}$.

Os profissionais precisam ser sensíveis e humanizados diante do sofrimento humano, para promoção de uma assistência integral de qualidade e individualizada, considerando as necessidades do adolescente em todas as suas dimensóes?.

Diante desse cenário, reflexôes e questionamentos surgem sobre o adolescente com câncer, fatos estes que serviram de mola propulsora para a pesquisa nessa temática a qual buscou responder à questão de pesquisa: Qual a percepçáo do adolescente oncológico frente à sua condição de adoecimento? E teve por objetivo: compreender a percepção do adolescente frente à sua condição de adoecimento oncológico.

\section{MÉTODO}

Trata-se de uma pesquisa exploratória, descritiva, de abordagem qualitativa, com uso da técnica do discurso do sujeito coletivo (DSC) ${ }^{10}$ realizada no período de junho a agosto de 2019, na unidade de internação do Centro Especializado em Oncologia Pediátrica, de um hospital universitário, referência Estadual de Pernambuco, para crianças e adolescentes com câncer. O setor de internação hospitalar conta com dez enfermarias de três leitos cada, distribuídas em dois andares, onde menores de 18 anos recebem tratamento para câncer.

Os pesquisadores elaboraram um questionário com questôes sociodemográficas e clínicas com perguntas sobre idade, sexo, cor, escolaridade (Ensino Fundamental I: $1^{\circ}$ ao $5^{\circ}$ ano, alunos na faixa etária de 6 a 10 anos; Ensino Fundamental II: $6^{\circ}$ ao $9^{\circ}$ ano, alunos na faixa etária de 11 a 14 anos; Ensino Médio: $1^{\circ}$ ao $3^{\circ}$ ano, alunos na faixa etária de 15 a 17 anos), procedência, renda familiar (salário mínimo = R \$998,00), diagnóstico e ano do diagnóstico para caracterização dos participantes. As entrevistas foram guiadas pelos seguintes questionamentos: Para você, como é estar doente? O que você pensa sobre o seu futuro? Como você se relaciona com os seus familiares e a equipe de saúde? Incialmente, foram entrevistados três adolescentes, incluídos neste estudo, para checar se os questionamentos trariam resposta ao objetivo do estudo.

As entrevistas individuais foram realizadas em sala privativa, no mesmo andar da enfermaria, por uma pesquisadora, membra da equipe de pesquisadores, treinada para realizar as entrevistas, em virtude da experiência de interação efetiva com adolescentes, além de desenvolver trabalho voluntário no local do estudo e estar familiarizada com eles. $\mathrm{O}$ adolescente e seu responsável foram convidados pessoalmente a participarem e receberam informaçóes sobre a pesquisa e quanto aos seus direitos e preservaçáo do anonimato, sigilo e confidencialidade de sua fala. O Termo de Consentimento Livre e Esclarecido foi assinado pelo responsável, que permaneceu acompanhando o adolescente durante a entrevista, e o Termo de Assentimento Livre e 
Esclarecido assinado pelo adolescente. A duração média das entrevistas foi de 35 minutos de gravação, transcritas na íntegra para preservar a originalidade dos depoimentos. Posteriormente, os adolescentes leram suas falas, e não houve correçóes.

Não houve recusa em participar da pesquisa. No período da coleta, 13 adolescentes estavam internados no local do estudo, e foram incluídos porque atenderam aos critérios de inclusão: ser paciente oncológico na faixa etária de $12 \mathrm{a}<18$ anos de idade, definida pelo Estatuto da Criança e do Adolescente e Sociedade Brasileira de Pediatria, internados no local do estudo no período da coleta, e estar em condição clínica favorável para participar da entrevista. O critério de exclusão foi o déficit na articulação das palavras.

Com uso da técnica do DSC, foram possíveis a tabulação e a organização dos conteúdos das opiniôes de sentido semelhante, presentes nos diferentes depoimentos dos adolescentes. Para produzir o DSC, incialmente, foi realizada leitura de cada resposta, nas transcriçóes literais e na íntegra das entrevistas gravadas de cada adolescente participante, e selecionados os trechos no conteúdo verbal que melhor descrevia sua resposta a cada um dos questionamentos, as expressões-chaves. Em seguida, foram identificadas, nesses recortes de falas significativas, as ideias centrais, que se constituem de palavras ou expressóes linguísticas que revelaram o sentido presente nesses depoimentos, e a ancoragem, quando presente, que traduzia as ideologias ou crenças explícitas nesse conteúdo verbal ${ }^{11}$.

Por fim, as expressōes-chaves que tinham a ideia central e/ou a ancoragem de sentido semelhante ou complementar foram agrupadas para representar a percepçáo da coletividade; desta forma, foram compostos os vários discursos-síntese que são os DSC redigidos na primeira pessoa do singular, descritos nos resultados ${ }^{11}$.

Os depoimentos dos participantes foram codificados com a letra A da palavra adolescente seguida do número da ordem da entrevista para garantir o anonimato.

Para relatar os aspectos importantes desta pesquisa, foram seguidas as recomendaçôes do guideline Consolidated criteria for reporting qualitative research ${ }^{12}$ (COREQ), e respeitados os princípios bioéticos em conformidade com a Resoluçáo n. ${ }^{0} 466 / 2012^{13}$ e n. ${ }^{\circ} 510 / 2016^{14}$ do Conselho Nacional de Saúde do Ministério da Saúde. Este estudo foi aprovado pelo Comitê de Ética em Pesquisa (CEP) do Complexo Hospitalar HUOC/Procape sob o número CAAE: 13218419.8 .0000 .5192 e parecer 3.360.038.

\section{RESULTADOS}

Participaram do estudo 13 adolescentes, na faixa etária de 12 a 17 anos, sete do sexo masculino e seis do sexo feminino. Em relação à procedência, nove eram do interior do Estado de Pernambuco, três da região metropolitana do Recife/PE, e um de outro Estado do Nordeste.

Entre os diagnósticos encontrados, nove foram leucemias e linfomas e quatro tumores sólidos. Em relação ao tempo de diagnóstico, nove foram no transcorrer do ano de 2019 e três em 2016, 2017 e 2018, respectivamente. Dos 13 adolescentes da amostra, seis possuíam histórico familiar de neoplasia. Em relação à etnia, nove adolescentes se autodeclararam pardos, dois negros e dois brancos.

A renda familiar de 11 adolescentes era de um salário mínimo ou menos, dois com renda familiar de dois salários mínimos. Em relação à escolaridade, nove possuíam o Ensino Fundamental incompleto, dois Ensino Fundamental II incompleto, e dois Ensino Médio completo.

A partir da análise dos depoimentos dos adolescentes, emergiram oito ideias centrais que traduzem a percepção do adolescente com câncer sobre o seu adoecimento, descritas no DSC.

Questão analisada: Para você, como é estar doente?

a) Estar doente é ruim porque limita rotinas da vida normal

DSC: É muito ruim, não posso fazer nada, nem comer o que eu quero, só fico deitado na cama, náo posso passear para onde eu realmente queria. Estressante! Essa doença é muito chata, tia, não posso fazer nada, só vendo TV, depois dessa doença nem para escola eu vou, porque o hospital é longe da escola e de casa. Perdi o Enem. É ruim, porque eu gosto de festa, sou festeira e não posso curtir com meus amigos. Horrível ficar doente, ainda mais com essa doença, ficar doente é ruim! É chato porque precisa internar, chato, não posso fazer nada e já estou aqui há quatro meses internado sem ir para casa, ruim, só fico no quarto, mas fazer o que? É bem ruim mesmo! Mas precisa tratar para poder viver, porque ela mata rápido o povo $(\mathrm{A} 1, \mathrm{~A} 2, \mathrm{~A} 3$, A4, A6, A7, A8, A10, A11, A12).

Para o adolescente, adoecer de câncer é ruim porque, além de alterar sua rotina de vida diária, com as hospitalizaçôes, impede que ele estude, que vá a festas, que conviva com os amigos, e essa é a perda mais sentida e descrita por ele.

b) O tratamento é doloroso e altera minha imagem corporal 
DSC: Sinto dor, e fico sendo furado o tempo inteiro quando perco veia, fico enjoada quando tomo a quimioterapia. Me afastei de todo mundo por conta do meu cabelo caindo, perdi uma perna por conta do câncer, os médicos disseram que foi porque cheguei aqui tarde, é porque eu demorei um ano até descobri o que eu tinha. Fiquei chateada porque por conta do tumor fiz histerectomia, ou seja, não posso mais ter filho. É ruim quando algumas pessoas ficam olhando para mim meio de lado, achando estranho eu estar de máscara e sem cabelo, acho que algumas deve achar que é uma doença que pode passar para outra pessoa (A1, A3, A6, A10, A13).

Para o adolescente, o câncer tem se mostrado como doença devastadora, que carrega consigo o estigma da morte, que mutila, altera a imagem corporal e, muitas vezes, ele passa a conviver com a discriminação e preconceitos.

c) Estar doente tem um lado bom

DSC: Olha, eu pensei que fosse pior, mas estou de boas. Já estou bem de novo. O bom é que eu durmo muito por conta dos remédios de enjoo e eu amo dormir. Quando eu melhorar um pouco vou conhecer o cinema daqui, na minha cidade não tem cinema. Pelo menos vou ter mais tempo para estudar aqui internado. Aqui é bom, tenho muitos amigos aqui agora também (A5, A6, A7, A8, A9).

Apesar de toda negatividade trazida pelo câncer, o adolescente ainda consegue vislumbrar um lado positivo, a partir de possibilidades oferecidas pelo seu contexto de adoecimento.

Questão analisada: O que você pensa sobre o seu futuro?

a) Ficar curado e retomar planos para minha vida

DSC: Ficar curado logo, não precisar mais vir para hospital para nada mais, nunca mais precisar vir, não precisar ficar aqui mais, só quero poder sair logo daqui e poder voltar para minha casa, ir logo para casa. Ficar curado para sempre dessa vez! E principalmente não precisar ser furado e viajar muito também e viajar para outros países. Ficar bom logo desse troço chato! Curado dessa doença, e fazer faculdade de estética, estou quase ficando atrasada para entrar na faculdade, mas acho que vai dar certo. Ficar curada para sempre, passar em medicina e claro fazer especializaçáo em oncologia clínica. Ficar curada e fazer minha faculdade de direito, virar jogador de futebol ou policial, virar youtuber para continuar gravando meus vídeos, eu já faço tia, mostro minha vida no hospital. Poder trabalhar para ajudar minha família. Ficar curado, voltar para minha vida normal, se só isso acontecer já está ótimo (A1, A2, A3, A4, A5, A6, A7, A8, A9, A10, A11, A12, A13).

Os resultados da pesquisa evidenciaram que o adolescente com câncer não pensa em sua finitude, mantém seu otimismo e planos de vida após sua cura. Planeja retomar seus estudos, fazer faculdade, viajar, trabalhar para ajudar financeiramente sua família, e, principalmente, náo precisar mais de tratamento e nem de internamento.

Questão analisada: Como você se relaciona com os seus familiares e a equipe de saúde?

a) O hospital e a equipe de saúde são acolhedores

DSC: O hospital é legal, sou muito amiga do pessoal do hospital, são todos muito bons. Eu gosto daqui e de todos que trabalham aqui, porque aqui é massa, aqui eu tenho tudo até cama com ar-condicionado, e tratam bem eu e minha mãe. São bons, eu não tenho o que reclamar de ninguém daqui. $\mathrm{O}$ pessoal daqui eu amo, são legais, são todos bons, eu gosto muito daqui. Eu gosto de ficar no quarto com mais dois amigos, como o hospital daqui. Aqui no hospital todo mundo é legal, gosto de todos do hospital (A1, A2, A3, A4, A5, A6, A7, A8, A9, A10, A11, A13).

Os resultados da pesquisa mostram que para o adolescente são importantes o acolhimento pelo profissional de saúde, o conforto oferecido pelo serviço hospitalar e a possibilidade de criar laços de amizade.

b) Falta empatia e acolhimento adequado

DSC: $\mathrm{O}$ povo que trabalha aqui, alguns às vezes são legais, mais ou menos. Antes eu estava em hospital muito ruim, no hospital antigo eu dormia na cadeira, sem comida, o povo todo chato. Aqui tem um ou outro emburrado, mas foi pior no outro hospital, a médica deu o diagnóstico de câncer quando eu estava sozinha, nem esperou a minha mãe chegar e até eu sei que isso é errado, eu sou de menor. Fiquei desesperada sozinha! $\mathrm{O}$ pessoal que trabalha aqui uns não são legais, alguns técnicos têm cara feia, têm uns que não dão muito atenção para mim! Quando interno, não gosto de ficar com minha tia, ela é evangélica e não deixa eu me arrumar, passar batom, ela diz que eu estou aqui para me tratar e não para ficar arrumada, bonita (A2, A4, A6, A7, A8, A11, A13). 
$\mathrm{Na}$ fala do adolescente, muitas vezes, a assistência prestada por alguns profissionais é marcada pela indiferença, falta de sensibilidade e amor, inclusive por familiares que o acompanha durante o internamento.

c) Humanização na assistência

DSC: Quando a brinquedoteca está aberta, eu amo ir para lá com os voluntários. Gosto de um plantão que tem a noite que a enfermeira traz filme e pipoca, a gente faz cinema! É legal, conto os dias para ela voltar de novo! Eu só gosto de uma enfermeira que me fura, porque ela brinca, não gosto que ninguém mais me fure (A1, A7, A10).

Quando o adolescente recebe uma assistência humanizada até momentos dolorosos são aceitos com mais facilidade, porque a humanização cria vínculo de segurança entre profissional-paciente.

\section{d) Apoio familiar}

DSC: Sempre falo com minha família por videochamada, só fico aqui com minha mãe ou meu pai, às vezes eu queria ficar com os dois junto comigo. Minha mãe não sai de perto de mim e eu a amo. Sou muito amiga da minha mãe e minha mãe está sempre comigo, às vezes me irrito porque ela fica o tempo todo perguntando se eu estou bem. Minha família está sempre junto de mim, minha máe me acompanha em tudo. Minha família élegal, mas às vezes minha mãe não pode ficar aqui comigo, precisa trabalhar, aí quem fica é minha vó. Minha família está sempre comigo, minha tia sempre fica comigo quando eu estou internada, minha mãe precisa trabalhar. Minha vó está sempre aqui comigo me ajudando e perguntando o tempo todo se estou bem, mandando eu comer, mandando-me levantar da cama, mandando eu sorri, ela gosta de mandar [risos]. Eu prefiro quando meu pai fica comigo quando estou com minha imunidade baixa, e interno, minha mãe quase sempre fica chorando porque fica preocupada, então prefiro que ela fique em casa e não me veja com dor (A1, A2, A3, A5, A6, A7, A8, A9, A10, A11, A12).

No discurso do adolescente, a família demonstra seu cuidado e afeto, os vínculos são fortes apesar da distância. A família se reveza para cuidar do adolescente durante o internamento hospitalar por causa da necessidade de trabalhar, e estão sempre checando se o adolescente se sente bem e sem dor, e o adolescente percebe todo esse apoio e cuidado familiar.

Os resultados mostram a percepçáo do adolescente sobre os aspectos de sua vida relacionados à assistência hospitalar, seus vínculos familiares e profissional-paciente, $\mathrm{o}$ apoio que recebe, o impacto do adoecer, sua perspectiva de cura e retomada de uma vida normal, com planos para o futuro, como trabalho, filhos, entre outros.

\section{DISCUSSÃO}

A mudança de rotina da vida cotidiana durante o processo de adoecimento é mais impactante do que a própria doença. Na percepção do adolescente, o fato de estar com câncer, aparentemente, não é tão importante, mas sim a limitação e impedimento de não poder fazer o que gosta por causa da doença e tratamento, porque suas atividades rotineiras são modificadas ${ }^{15}$. Apesar de todas as limitaçóes impostas pelo adoecimento, a percepção trazida no DSC evidencia que o adolescente ainda mantém um olhar positivo, capaz de suplantar o sofrimento, e vislumbrar aspectos positivos, para além dos aspectos negativos que envolvem a doença e as hospitalizaçôes.

Os adolescentes com câncer tiveram as rotinas de vida alteradas pelo tratamento e ficaram afastados do convívio social, esse fato pode causar certa dificuldade nos relacionamentos emocionalmente importantes, mudanças na imagem corporal que podem fazê-lo se sentir menos atraente ${ }^{16}$, por isso é necessário atentar para alguns sinais de alerta de isolamento, baixa autoestima, entre outros sinais que possam identificar uma adolescência fora dos padróes.

O tratamento oncológico requer procedimentos invasivos, quimioterapia, radioterapia, cirurgia e outras abordagens terapêuticas que trazem efeitos adversos como os enjoos, edema, vômitos, cefaleia, além de alteraçóes na autoimagem como a queda de cabelo, mutilaçóes, que podem repercutir negativamente nas dimensóes psicossocial e emocional do adolescente ${ }^{17}$. O DSC retrata o quanto é doloroso, árduo e cheio de sentimentos ambíguos $o$ adoecer de câncer.

E essas perturbaçóes da autoimagem impostas pelo tratamento, sentidas pelos pacientes, podem refletir um alto nível de resiliência. É na adversidade que eles aprendem a ressignificar suas crenças e se fortalecerem para o enfrentamento da doença, e é diante dos problemas que encontram saídas e percebem que a vida vale a pena viver ${ }^{18}$.

É nessa perspectiva que o discurso do adolescente com câncer, neste estudo, evidencia o objetivo principal do tratamento que é a obtenção da cura e/ou a liberação para uma alta segura, e retorno aos planos de sua vida e, para que isso ocorra, a assistência terapêutica humanizada pode amenizar o sofrimento e minimizar o desajuste emocional ${ }^{19}$, para que estes náo se tornem um impedimento ao longo dessa trajetória.

Muitas vezes, o caminho percorrido até a chegada ao hospital de referência em oncologia é lento, podendo trazer 
consequências para o paciente por conta do diagnóstico tardio e atraso no início do tratamento, seja ele por falta de vaga e/ou por falta de verba para medicamentos. As fragilidades do Sistema Único de Saúde levam ao atraso no tratamento e assistência, com excesso de burocracia e deficiência nas orientaçôes sobre a patologia ${ }^{20}$.

As atitudes do outro, por vezes, incomoda, podendo intensificar sentimentos de isolamento entre os adolescentes com câncer. O preconceito é presente quando se trata das sequelas causadas pelo tratamento, em virtude da aparência sofrida, carregada de cicatrizes e amputaçóes de membros, que podem traduzir uma possível desinformação e curiosidade das pessoas diante da doença. Nesse cenário, as redes sociais podem ajudar a desmistificá-lo, como identificado nos resultados dessa pesquisa $^{21,22}$.

A expectativa de futuro, contrapondo algumas ideias de que apenas pacientes com chances de cura e com uma boa expectativa de vida e sobrevida podiam e conseguiam explanar desejos e pensamentos para o futuro, demonstra que aqueles em processo de paliação também explanam pensamentos e planejamentos sobre o futuro e esperança de uma sobrevida prolongada com qualidade, destacando a importância de traçar estratégias para adaptar o tempo junto a família e amigos ${ }^{23}$.

Considerando que o adolescente busca como consequência do tratamento a cura e uma melhor qualidade de vida, a resiliência diante das adversidades trazidas pela vivência do adoecimento permite a readaptação e a possibilidade de novas perspectivas e planos para o futuro ${ }^{24}$.

O DSC revelou a importância da cura para o alcance dos planos de vida traçados por meio dela, de que seus hábitos da vida cotidiana, tomados pelo adoecimento, serão devolvidos e, assim, planos profissionais poderão ser realizados. Estudo com adolescentes que sobreviveram ao câncer encontrou dados semelhantes, o período difícil do tratamento permitiu vislumbrar um novo significado de vida e estes encaravam o período pós-tratamento como uma oportunidade para seguir uma vida normal ${ }^{9}$.

As redes sociais, plataformas on-line que permitem a interação social, fazem parte da vida cotidiana das pessoas de um modo geral e dos adolescentes também, por meio das quais comunicam-se compartilhando, produzindo e consumindo conteúdos digitais, que possibilitam a convivência on-line com outras pessoas com as quais conversam sobre determinados assuntos de interesse e entretenimento ${ }^{25}$.

As redes sociais têm possibilitado ao adolescente pensar no futuro. Essas ferramentas tecnológicas facilitam a comunicação no dia a dia com o mundo fora do hospital, com pacientes de outras enfermarias, e também para amenizar a saudade dos familiares em casa e até produzir campanhas para arrecadação de doaçóes durante o tratamento. Outros adolescentes passam seu tempo mostrando sua rotina frente à sua condição de adoecimento aos internautas, para encorajar qualquer pessoa que esteja passando por uma situaçáo difícil, claro sob supervisão do responsável, uma vez que a utilização de redes sociais não é isenta de riscos ${ }^{26}$.

Essas relaçóes que o adolescente mantém com seus amigos da vida real e virtual, intermediada pelas redes sociais, apesar dos riscos, traz ao adolescente o sentimento de pertencer à comunidade, de conexáo com seus pares, e isso pode contribuir para manter uma autoestima elevada, indispensável no processo do adolescer e do adoecimento $^{27}$.

A rede social possui características funcionais, efetivas e essenciais para o bem-estar de pacientes com câncer, para fornecimento de apoio. Melhorando assim a qualidade de vida e autoestima durante todo o processo de diagnóstico, tratamento e pós-tratamento, tornando essa trajetória menos dolorosa. Entre as funções consideradas normais no cotidiano, companhia social é a principal exercida pela rede ${ }^{28}$.

Na percepção do adolescente, os profissionais precisam ter empatia diante do sofrimento humano, o envolvimento na relação profissional-paciente é imprescindível para uma formação de vínculo e confiança, com intuito de ofertar cuidado e conforto não só para o adolescente, mas também para a família envolvida nesse processo?

A importância da humanização na assistência e nas relaçôes familiares, trazida pelo DSC, evidenciou que, para o adolescente, os cuidados com a saúde e a humanização da assistência caminham entrelaçados, e um não pode prosseguir sem a presença do outro. Compreender como a família vivencia o adoecimento possibilita aos profissionais de saúde, e particularmente aos enfermeiros, reconhecer a relevância de prestar cuidado integral e humanizado ${ }^{20}$.

Refletir sobre a percepção do adolescente e o seu adoecer possibilita mudanças nas práticas assistenciais dos enfermeiros, tornando-as humanizadas e acolhedoras, o que faz diferença no tratamento, minimiza a dor física e alegra os adolescentes, que aguardam com muita expectativa receber o cuidado que lhes é devido ${ }^{29}$. A mudança de humor para melhor, após os cuidados humanizados prestados, e a utilizaçáo dos recursos terapêuticos não farmacológicos pelos profissionais de saúde, como aqueles relatados pelos adolescentes neste estudo, traduzem essa diferença.

Os recursos terapêuticos não farmacológicos são importantes no sentido de minimizar o desconforto do paciente, são eles: massagens de conforto, mudanças de rotinas mesmo no âmbito hospitalar, uso de compressas, 
entre outros. Atividades artísticas também auxiliam, melhorando a expressão emocional, a autoestima, a comunicação, o convívio social com outros pacientes, gerando bem-estar. Por esse motivo, existem vários grupos de apoio à criança com câncer pelo mundo, fazendo o possível para promover sorrisos e, deste modo, auxiliam no lidar com a dor e a deixar de lado um pouco o ambiente onde se encontram ${ }^{30}$.

Nesta pesquisa, por causa da distância entre o local de residência e o hospital onde estavam hospitalizados, muitos eram acompanhados por familiares, como irmão, tio, avós. Consequentemente, a saudade dos pais, que precisavam manter seus empregos para o sustento da família, era sentida e, muitas vezes, o familiar que o acompanhava não tinha a mesma postura humanizada; no entanto, as relaçóes de cuidado precisam estar pautadas em uma interação de respeito e não de domínio sobre o outro ${ }^{6}$.

Diante da empatia e humanização, o foco não está apenas nos profissionais de saúde, mas também nos familiares que estão acompanhando o adolescente, muitas vezes o impedimento do uso de objetos simples, como um batom, é sentido porque foi retirado não pela doença, e sim pela postura que o familiar resolveu adotar ${ }^{6}$.

É preciso olhar o adolescente individualizado, como uma pessoa que tem percepçóes e total aptidão para expressá-las. É importante que os profissionais de saúde e os familiares mantenham uma relação efetiva e afetiva com o adolescente, para que possam lançar mão de estratégias e fornecer apoio eficaz, o que requer conhecer a perspectiva e características das etapas do seu desenvolvimento, com intuito de compreender seus sentimentos ${ }^{9}$.

Nem sempre um problema ou sofrimento para a equipe e a família é um problema ou sofrimento para o adolescente. Essa compreensão é fundamental para mostrar que opinióes vivenciadas sobre problemas e sofrimentos perpassam de maneira distinta. $\mathrm{O}$ adolescente no seu processo de adoecimento, para o enfretamento do câncer, utiliza recursos internos como a esperança e a confiança, assim como os externos, como a rede social, próprios da sua fase de vida ${ }^{24}$.

$\mathrm{O}$ adolescente, sendo o protagonista da sua condição de adoecimento, é quem pode falar como se sente, o que pensa, o que espera da vida e como vê o adoecer de câncer; somente após ouvi-lo, conhecendo sua realidade, será possível refletir e repensar sobre a humanização nos cuidados da enfermagem e de toda a equipe de saúde ${ }^{31}$.

$\mathrm{O}$ câncer traz consequências diretas para o paciente e toda sua família, por motivar limitaçóes em sua autonomia. Em contrapartida, a família e os amigos são importantes fontes de apoio para o processo da doença. Destacando que os profissionais de saúde são citados, principalmente os enfermeiros, que diretamente estão presentes em todo o processo, contribuindo por meio de uma escuta terapêutica qualificada ${ }^{7}$ para a promoção de um cuidado holístico e humanizado.

Este estudo apresentou como limitação sua realização em um único serviço de saúde, que, apesar de ser referência no Estado de Pernambuco para o tratamento do câncer de crianças e adolescentes, pode não traduzir outras realidades do país.

\section{CONCLUSÃO}

O presente estudo revelou, por meio do discurso de adolescentes, sua percepção do adoecimento e tratamento do câncer, e como estes modificam as rotinas da vida cotidiana, causando distanciamento do convívio familiar e amigos.

Os sentimentos vivenciados com olhar do adolescer, próprios da faixa etária, muitas vezes diferem do sofrimento da família e da equipe de saúde, porque, para o adolescente, o adoecimento vai além da condição de saúde física, influencia todo o meio social, econômico, familiar, hospitalar, repercuti sobre o psicológico, e nas perspectivas de futuro, gera fragilidade na qualidade de vida, no convívio com a doença, e naqueles envolvidos que contribuem para o adolescente durante essa trajetória.

$\mathrm{O}$ adolescente percebe o profissional de saúde que presta assistência humanizada e utiliza a ferramenta da escuta terapêutica como um diferencial no tratamento, e que o uso de recursos não farmacológicos possibilita minimizar a dor física, e fortalecer o vínculo profissional-paciente.

Este estudo permitiu, ainda, compreender que o adolescente deve ser visto como protagonista do seu contexto de adoecimento, e destacou a importância de ouvir dele como é conviver com o câncer, o relato de sua trajetória desde a descoberta do seu diagnóstico, com a presença de sentimentos como o medo e insegurança, até o tratamento, hospitalizações e assistência recebida. Discursos marcados pela dor, luta, resiliência, e adaptação a uma nova rotina imposta pela doença, sem, no entanto, perder a esperança de superação e retomada de seus planos de vida para o futuro.

\section{CONTRIBUIÇÕES}

Todos os autores contribuíram substancialmente na concepção e/ou planejamento do estudo; na obtenção, análise e/ou interpretação dos dados; na redação e revisão crítica; e aprovaram a versão final a ser publicada.

\section{DECLARAÇÃO DE CONFLITO DE INTERESSES}

Nada a declarar. 


\section{FONTES DE FINANCIAMENTO}

Não há.

\section{REFERÊNCIAS}

1. Bray F, Ferlay J, Soerjomataram I, et al. Global cancer statistics 2018: GLOBOCAN estimates of incidence and mortality worldwide for 36 cancers in 185 countries. CA Cancer J Clin. 2018;68(6):394-424. doi: https://doi. org/10.3322/caac. 21492

2. Force LM, Abdollahpour I, Advani SM, et al. The global burden of childhood and adolescent cancer in 2017: an analysis of the Global Burden of Disease Study 2017. Lancet Oncol. 2019;20(9):1211-25. doi: https://doi. org/10.1016/S1470-2045(19)30339-0

3. Instituto Nacional de Câncer José Alencar Gomes da Silva. Estimativa 2020: incidência de câncer no Brasil [Internet]. Rio de Janeiro: INCA; 2019 [acesso 2020 abr 25]. Disponível em: https://www.inca.gov.br/ublicaçôes/ livros/estimativa-2020-incidencia-de-cancer-no-brasil

4. Ministério da Saúde (BR). Secretaria de Atenção à saúde, Departamento de Atenção Especializada e Temáticas. Protocolo de diagnóstico precoce do câncer pediátrico [Internet]. Brasília: Ministério da saúde; 2017 [acesso 2020 abr 25]. Disponível em: https://bvsms.saude.gov. br/bvs/publicaçôes/protocolo_diagnostico_precoce_ cancer_pediatrico.pdf

5. Santos RCS, Silva JLM, Custódio LMG. A doença crônica e o adolescer: efeitos do adoecimento e do câncer no desenvolvimento do adolescente. Psicologia.pt [Internet]. 2018 jan 7 [acesso 2020 set 13]. Disponível em: https:// www.psicologia.pt/artigos/textos/A1160.pdf

6. Silva-Rodrigues FM, Vulczak VLS, Alencar CF, et al. Concepçóes dos pais acerca da doença oncológica e do tratamento quimioterápico de seus filhos. Rev Enferm UFSM. 2020;10:e33:1-17. doi: https:/doi. org/10.5902/2179769235898

7. Andrade GB, Pedroso VSM, Weykamp JM, et al. Cuidados paliativos e a importância da comunicaçáo entre o enfermeiro e paciente, familiar e cuidador. Rev Pesqui Cuid Fundam Online. 2019;11(3):713-7. doi: https://doi. org/10.9789/2175-5361.2019.v11i3.713-717

8. Souza SAL, Silveira LMC. (Re)Conhecendo a escuta como recurso terapêutico no cuidado à saúde da mulher. Rev Psicol Saúde. 2019;11(1):19-42. doi: https://doi. org/10.20435/pssa.v0i0.571

9. Valizadeh L, Zamanzadeh V, Ghahremanian A, et al. Experience of adolescent survivors of childhood cancer about self-care needs: a content analysis. Asia Pac J Oncol Nurs. 2020;7(1):72-80. doi: https://doi.org/10.4103/ apjon.apjon_47_19

10. Lefevre F, Lefevre AMC. Discurso do sujeito coletivo: representaçóes sociais e intervençóes comunicativas.
Texto Contexto Enferm. 2014;23(2):502-7. doi: https:// doi.org/10.1590/0104-07072014000000014

11. Brandalise MAT. Tecnologias de informação e comunicação nas escolas públicas paranaenses: avaliação de uma política educacional em ação. Educ Rev. 2019;35:e206349. doi: https://doi.org/10.1590/01024698206349

12. Moher D, Altman DG, Schulz KF, et al., editors. Guidelines for reporting health research: a user's manual [Internet]. New Jersey: John Wiley \& Sons; 2014. Chapter 21, COREQ (Consolidated Criteria for Reporting Qualitative Studies); [cited 2020 Aug 13]; p. 214-26. Available from: https://onlinelibrary.wiley.com/ doi/abs/10.1002/9781118715598.ch21

13. Conselho Nacional de Saúde (BR). Resolução no 466, de 12 de dezembro de 2012. Aprova as diretrizes e normas regulamentadoras de pesquisas envolvendo seres humanos. Diário Oficial da União, Brasília, DF. 2013 jun 13; Seção 1:59.

14. Conselho Nacional de Saúde (BR). Resolução no 510, de 7 de abril de 2016. Dispóe sobre as normas aplicáveis a pesquisas em Ciências Humanas e Sociais cujos procedimentos metodológicos envolvam a utilização de dados diretamente obtidos com os participantes ou de informaçôes identificáveis ou que possam acarretar riscos maiores do que os existentes na vida cotidiana, na forma definida nesta Resolução. Diário Oficial da União. 2016 maio 24; Edição98, Seção I:44.

15. Freitas JAL, Oliveira BLG. Aspectos psicológicos envolvidos na sobrevivência do câncer infantil. Rev UNINGÁ [Internet]. 2018 [acesso 2020 ago 08];55(2):113. Disponível em: http://revista.uninga.br/index.php/ uninga/article/view/76/1680

16. Veneroni L, Bagliacca EP, Sironi G, et al. Investigating sexuality in adolescents with cancer: patients talk of their experiences. Pediatr Hematol Oncol. 2020;37(3):223-4. doi: https://doi.org/10.1080/08880018.2020.1712502

17. Rodrigues ACC, Tavares AB, Teixeira AIB. O "Adolescer" e a experiência de adoecimento por câncer. Rev Cient Multi Núcl Conhecimento [Internet]. 2017 [acesso 2020 set 13];01(Ed. 5):784-98. Disponível em: https://www. nucleodoconhecimento.com.br/psicologia/experienciaadoecimento-cancer

18. Lins FG, Nascimento HB, Sória DAC, et al. Autoimagem e resiliência de pacientes oncológicos. Rev Pesqui Cuid Fundam Online. 2020;12:497-502. doi: https://doi. org/10.9789/2175-5361.rpcfo.v12.8565

19. Bulla ML, Maia EBS, Ribeiro CA, et al. O mundo do adolescente após a revelação do diagnóstico de câncer. Reme, Rev Min Enferm. 2015;19(3):681-8. doi: https:// doi.org/10.5935/1415-2762.20150052

20. Souza JB, Walker F, Schleicher ML, et al. Assistência às mulheres mastectomizadas: percepçóes de familiares e o despertar da promoção da saúde. Rev Baiana Enferm. 
2019;33:1-9. doi: https://doi.org/10.18471/rbe. v33.33566

21. Porto RLA, Silva MRO, Castro EHB. A experiência do câncer infantil: enfrentando a facticidade. Rev Amazônica [Internet]. 2017 [acesso 2020 ago 08];19(2):100-19. Disponível em: https://periodicos.ufam.edu.br/index. php/amazonica/article/view/4538/3679

22. Almeida MD, Priszkulnik L. Vergonha e corpo na contemporaneidade: reflexóes para a oncologia pediátrica. Psicol Argum. 2018;36(91):122-39. doi: https://doi. org/10.7213/psicolargum.36.91.AO07

23. Delevatti VF, Salaza V, Schneider TMD, et al. Expectativa de vida e perspectiva de futuro em pacientes oncológicos: revisão sistemática. Psicol Pesq. 2018;12(1):15-22. doi: https://doi.org/10.24879/2018001200100328

24. Bicalho C, Araújo A, Botti NCL. Processo de adolescer relacionado ao adoecimento e tratamento do câncer. Psic Saúde Doenças. 2019;20(1):74-87. doi: https://doi. org/10.15309/19psd200106

25. Shah J, Das P, Muthiah N, et al. New age technology and social media: adolescent psychosocial implications and the need for protective measures. Curr Opin Pediatr. 2019;31(1):148-56. doi: https://doi.org/10.1097/ MOP.0000000000000714

26. Bordignon C, Bonamigo IS. Os jovens e as redes sociais virtuais. Pesqui Prát Psicossociais [Internet]. 2017 [acesso 2020 ago 08];12(2):310-26. Disponível em: http:// pepsic.bvsalud.org/scielo.php?script=sci_arttext \&pid $=$ S1809-89082017000200006

27. Rebelo AR, Lopes SV, Macedo LD, et al. Os adolescentes e as redes sociais. Adolesc Saude [Internet]. 2020 [acesso 2020 ago 08];17(2):84-90. Disponível em: chromeextension://efaidnbmnnnibpcajpcglclefindmkaj/viewer. html?pdfurl=https\%3A\%2F\%2Fcdn.publisher.gn 1 . link $\% 2$ Fadolescenciaesaude.com\%2Fpdf\%2Fv17n2a11. pdf\&clen $=874707 \&$ chunk $=$ true

28. Bard BA, Cano DS. O papel da rede social de apoio no tratamento de adultos com câncer. Mudanças, Psicol Saúde. 2018;26(1):23-33. doi: https://doi. org/10.15603/2176-1019/mud.v26n1p23-33

29. Paris de Souza I, Belatto R, Santos de Araújo LF, et al. Adolescer e adoecer na perspectiva de jovem família. Cienc Enferm. 2016;22(3):61-75. doi: https://doi. org/10.4067/S0717-95532016000300061

30. Rocha DM. Contributo das atividades artísticas no bem-estar e qualidade de vida de crianças em tratamento oncológico: um estudo no IPO do Porto e no GACC da Bahia [tese]. Portugal: Universidade do Minho; 2017.
31. Santos MFG, Almeida IS, Reis NSP, et al. A percepção da hospitalização pelos adolescentes: contribuiçóes para o cuidado de enfermagem. Rev Pesq Cuid Fundam online. 2018;10(3):663-8. doi: https://doi.org/10.9789/21755361.2018.v10i3.663-668 